\title{
Potential for HER-2/neu molecular targeted therapy for invasive bladder carcinoma: Comparative study of immunohistochemistry and fluorescent in situ hybridization
}

\author{
HIROYUKI MATSUBARA, YOSHIAKI YAMADA, KATSUYA NARUSE, KOGENTA NAKAMURA, \\ SHIGEYUKI AOKI, TOMOHIRO TAKI, MOTOI TOBIUME, KENJI ZENNAMI, \\ REMI KATSUDA and NOBUAKI HONDA
}

Department of Urology, Aichi Medical University School of Medicine, Aichi, Japan

Received July 28, 2007; Accepted September 18, 2007

\begin{abstract}
Analysis of HER-2/neu expression in invasive bladder carcinoma was performed in order to evaluate the potential for molecular targeted therapy targeting HER-2. The subjects were 40 patients who were pathologically diagnosed with invasive transitional cell carcinoma of the bladder (pT2 to pT4). A Hercep test kit was used to detect HER-2 expression, and a Path Vysion kit was used for gene amplification. On immunohistochemical (IHC) staining, the primary tumors were HER-2 positive in 17 patients (17/40, 42.5\%). According to the classification of grade, one Grade 2 patient $(1 / 3)$ and 16 Grade 3 patients $(16 / 37)$ were positive $(\mathrm{P}=0.99)$. According to the classification of stage, 12 pT2 patients $(12 / 22,54.5 \%)$, 2 pT3 patients $(2 / 13,15.3 \%)$, and 3 pT4 patients $(3 / 5,60 \%)$ were positive $(\mathrm{P}=0.55)$. Lymph node metastasis was found in 10 patients, and $3 \mathrm{pN} 2$ patients were HER-2 positive (3/6, $50 \%)(\mathrm{P}=0.32)$. A statistically significant difference was observed between HER-2-positive primary tumors and metastatic lymph nodes $(\mathrm{P}=0.02)$. In fluorescent in situ hybridization (FISH), HER-2/neu gene amplification was detected in the primary tumors in 5 patients $(5 / 40,12.5 \%)$. In all these patients, IHC staining was determined as $3^{+}$. Lymph node metastasis was found in $3 \mathrm{pN} 2$ patients $(3 / 6)(\mathrm{P}=0.32)$, and in these patients with HER-2/neu gene-amplified metastatic lymph nodes, the primary tumors were also positive for gene amplification $(\mathrm{P}=0.02)$. In these cases, IHC staining was $3^{+}$as well. The concordance rate of IHC-positive cases with cases positive for HER-2/neu gene amplification in FISH was $12.5 \%$ (5/40), and the concordance rate of $\mathrm{IHC} 3^{+}$and gene amplification was $71 \%$. This result suggests that, at present, patients who may potentially benefit from molecular targeted therapy targeting
\end{abstract}

Correspondence to: Dr Yoshiaki Yamada, Department of Urology, Aichi Medical University School of Medicine, Nagakute, Aichi 480-1195, Japan

E-mail: 101959@gk.amu.aichi-med-u.ac.jp

Key words: invasive bladder carcinoma, HER-2/neu, immunohistochemistry, molecular targeted therapy, fluorescent in situ hybridization
HER-2/neu for invasive bladder carcinoma should be identified by gene amplification analysis using FISH in IHC $3^{+}$patients. In addition, it suggested that efficacy of molecular targeted therapy can be expected even for patients with metastatic lymph nodes as long as the primary tumors are positive for HER-2 expression.

\section{Introduction}

Currently, the standard treatment for invasive bladder cancer without metastasis is considered to be radical cystectomy. However, the results of radical cystectomy are substantially influenced by the pathological stage and the presence or absence of lymph node metastasis at the time of surgery. The cause-specific survival rate has been reported to be favorable at approximately $70 \%$ when invasion was observed only in the tunica muscularis (pT2), whereas the rate was 30-40\% when invasion into the surrounding adipose tissue was observed (pT3), and approximately $20 \%$ when lymph node metastasis was noted $(1,2)$. In addition, after radical cystectomy, most recurrences were distant metastases, only approximately $10 \%$ being local recurrence (3). Therefore, it is more important to eradicate such micro-metastases that cannot be identified by imaging rather than to increase local curability, to improve the treatment results of radical cystectomy. Surgical resection is not sufficient for invasive bladder cancer with involvement outside the bladder wall or lymph node metastasis, and additional therapy is required.

Multi-drug combination chemotherapy with anti-cancer agents is commonly used to treat progressive bladder cancer that is unresectable or metastatic. M-VAC therapy is a typical chemotherapy regimen and has been the gold standard since Sternberg et al $(4,5)$ reported a response rate of $72 \%$ and complete remission rate of $36 \%$. However, subsequent studies have revealed that the therapy has a low response rate with a short duration of response, which lowers the prospect of longterm survival; there are often concerns about dose intensity because a large proportion of the targeted patients are elderly, and the high toxicity of the drug is a substantial physical burden to those many elderly patients with bladder cancer $(6,7)$. Moreover, at present, the standard treatment for M-VACresistant cancer has not been established. Therefore, the development of novel regimens replacing M-VAC therapy is 
Table I. Patient's characteristics.

\begin{tabular}{lc}
\hline No. of patients & 40 \\
Age (years) & $47-80$ \\
Average age (years) & $65.6 \pm 8.35$ \\
Median age (years) & 65 \\
Gender & Male, 37; female, 3 \\
T classification & pT2, 22; pT3, 13; pT4, 5 \\
N classification & pNO, 23; pN1, 4; pN2, 6; pNx, 7 \\
Grade & $\mathrm{G} 2,3 ; \mathrm{G} 3,37$ \\
\hline
\end{tabular}

on-going, and clinical trials of anti-cancer agents, mainly gemcitabine and taxane, are being conducted; however, their effectiveness is still under examination (8-10).

On the other hand, molecular targeted therapies for cancer are drugs developed to target changes in genes and molecules that are characteristic of cancer. Conventional anti-cancer agents primarily affect the process of nucleic acid, DNA, and microtubule synthesis etc., and exert anti-tumor effects. These agents, however, have limited effectiveness due to poor tumor selectivity, since they affect both normal and tumor cells. For conventional anti-cancer agents, therefore, the maximum tolerated dose without toxicity has been regarded as the optimal dose. However, molecular targeted therapeutic drugs generally have a weaker toxicity than anti-cancer agents. Moreover, these drugs can be administered safely even to elderly patients, which has been emphasized as an advantage. Furthermore, these drugs can be used in combination with existing anticancer agents, and are superior in that they can be used as a tailor-made treatment by coupling them with development of biomarkers.

In molecular targeted therapeutic drugs, the target should first be identified, and therapy should be limited to patients with the potential for responsiveness to molecular targeted therapy. A retrospective study of HER-2/neu expression by immunohistochemical (ICH) staining using a Hercep test kit (Dako Cytomation A/S, Carpinteria, CA) recommended by the Food and Drug Administration and gene amplification by fluorescent in situ hybridization (FISH) using a Path Vysion kit (Vysis, Downers Grove, IL) was performed in order to investigate the potential for molecular targeted therapy targeting HER-2 as an effective treatment for patients with invasive bladder carcinoma.

\section{Materials and methods}

Patients. This study included 40 patients who attended Aichi Medical University Hospital from January 2001 to December 2004, and were pathologically diagnosed with invasive bladder transitional cell carcinoma (pT2 to pT4). The diagnostic methods were radical cystectomy for 33 patients, and TUR-Bt for 7 patients. The patients were 47 to 80 years old (median, 65 years; mean, $65.6 \pm 8.4$ years); 37 were male and 3 were female. The pathological grade was 2 and 3 , in 3 and 37 patients, respectively. The stage was pT2, pT3 and pT4, in 29, 5 , and 6 patients, respectively. The $\mathrm{N}$ classification was $\mathrm{pN} 0$, $\mathrm{pN} 1, \mathrm{pN} 2$ and $\mathrm{pNx}$, in $23,4,6$, and 7 patients, respectively.
Histopathological grade was based on the World Health Organization (WHO) classification (11), and the TNM classification (12) was used to evaluate primary tumors and lymph node metastases.

This study was approved by the Institutional Review Board at Aichi Medical University (no. 275), and every patient gave consent after being sufficiently informed, before HER-2/neu examination. Table I shows the characteristics of the 40 patients.

IHC method and evaluation. Paraffin sections, $5 \mu \mathrm{m}$ thick, from bladder carcinoma samples taken at the operation were stained for HER-2 protein expression using a standardized Hercep test kit. The primary antibody in this assay is an affinity-purified rabbit polyclonal antiserum raised against an intracellular epitope of the human HER-2 molecule (Specification Sheet: K5205, Dako, USA). The staining procedure includes an antigen retrieval step consisting of a 40-min incubation in pH 6.0 citrate buffer (Target Retrieval, Dako) at $99^{\circ} \mathrm{C}$ in a water bath. Staining was performed using an automated staining apparatus for IHC (Autostainer, Dako) according to the manufacturer's guidelines. The slides were counterstained with haematoxylin. Each IHC experiment included a set of control slides. For the negative control, the primary antibody was replaced with an irrelevant, isotypematched antibody to control for nonspecific binding of the secondary antibody reagent. The positive control slide consisted of sections of cell blocks of the three breast-cancer cell lines SKBR 3, MDA-MB-175, and MDA-MB-231, which express 2.4 million, 92,000 and 22,000 HER-2 receptor molecules by Scatchard analysis, respectively, and correspond to HER-2 scores of $3^{+}, 1^{+}$and 0 , respectively, obtained by IHC. Histopathologic evaluation was performed and the staining results were interpreted by two experienced pathologists and graded into four levels according to the classification of Carter et al (13). We considered scores of $>2^{+}$as positive (Fig. 1).

FISH method and evaluation. In order to test whether amplification of the HER-2/neu gene occurred in bladder carcinoma, a FISH analysis was performed on a representative proportion of the tumors using the Path Vysion kit. The staining was performed on paraffin sections exactly according to the manufacturer's recommendations. Briefly, deparaffinized slides were treated with a protein-digesting enzyme at $37^{\circ} \mathrm{C}$ for $10 \mathrm{~min}$. Preparations were denatured in $70 \%$ formamide/ $2 \mathrm{X}$ standard saline citrate (SSC), $\mathrm{pH} 7.0$, at $72^{\circ} \mathrm{C}$, for $5 \mathrm{~min}$. Then, a solution containing the HER-2/neu probe coupled with Spectrum Orange and a specific probe for the centromere of chromosome 17 coupled with Spectrum Green were applied to the tissue sections at $37^{\circ} \mathrm{C}$ for $15 \mathrm{~h}$. After hybridization, the unannealed probe was washed in 2X SSC/NP40 $0.3 \%$ at $73^{\circ} \mathrm{C}$ for $2 \mathrm{~min}$. Nuclei were counterstained using a 4,6 diamidine, 2-phenylindol (DAPI)/antifade solution, and stored in darkness at $8^{\circ} \mathrm{C}$ until evaluation. In each preparative run, positive controls (i.e. paraffin sections of breast cancers known to be amplified for the HER-2/neu gene or Probe Check control slides supplied by the manufacturer) were included. A Leica DMRB microscope equipped with appropriate filters for DAPI, Spectrum Green and Spectrum Orange was used to score the number of signals per nucleus. Images were captured 


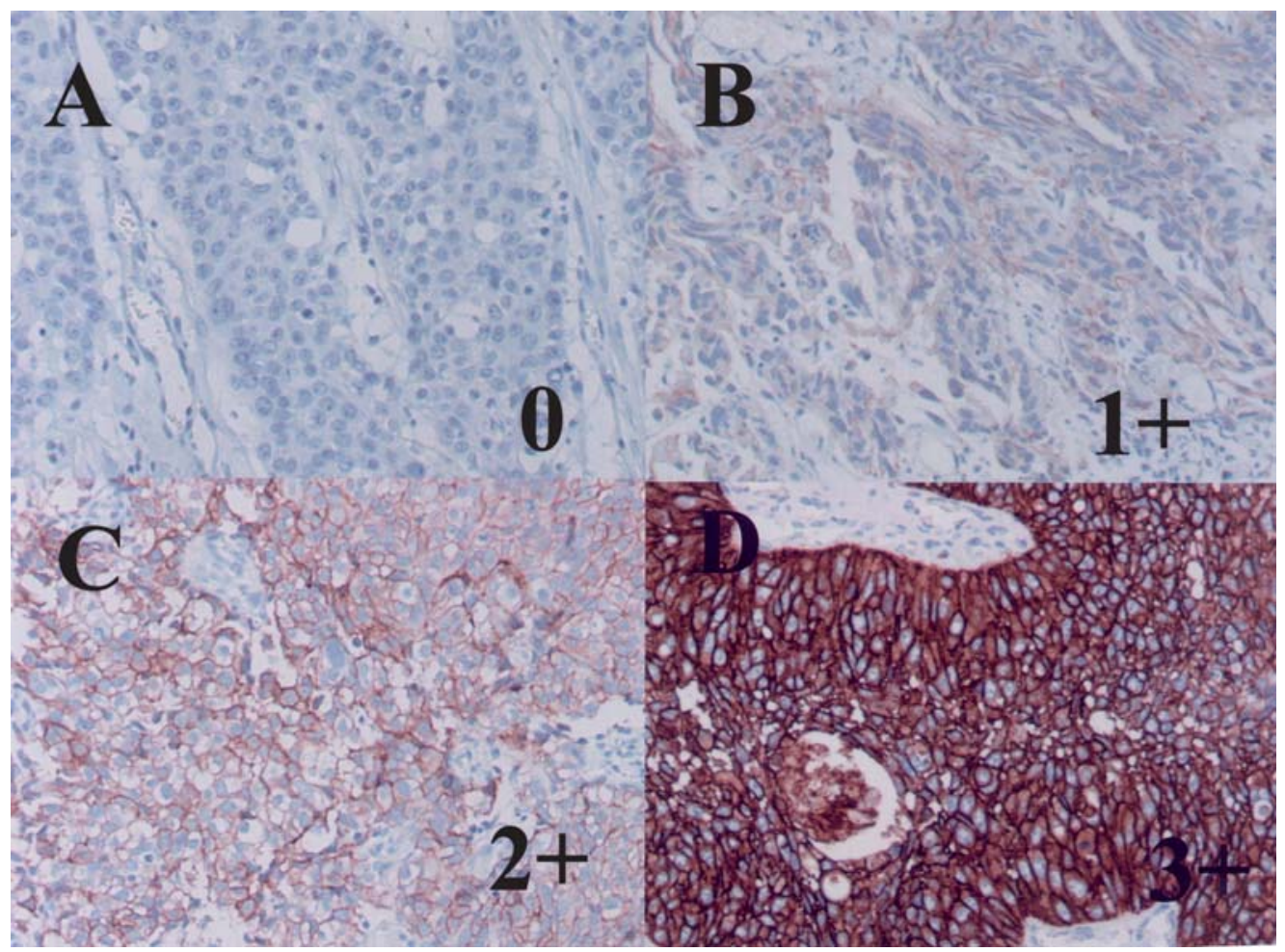

Figure 1. HER-2 expression in four primary tumors detected by immunohistochemistry using the Hercep test kit. (A) No staining or membrane staining observed in $<10 \%$ of tumor cells (HER-2 score 0 ) (x200). (B) Faint or barely perceptible membrane staining detected in $>10 \%$ of tumor cells: cells are stained only in part of their membrane (HER-2 score $1^{+}$) (x200). (C) Weak to moderate, complete membrane staining observed in $>10 \%$ of tumor cells $\left(\right.$ HER-2 score $2^{+}$) (x200). (D) Strong complete membrane staining observed in $>10 \%$ of tumor cells (HER-2 score $3^{+}$) (x200).

using a Quantics digital camera (Axioplan 2 imaging, Zeiss, Jena, Germany) and Quips FISH imaging software (Meta Cyte scanning image cytometer, Meta Systems, Altlussheim, Germany). The number of fluorescent signals was counted in 60 nuclei of invasive tumor cells in two distant areas of the section for each case. For each tumor, the mean number of signals per nucleus was determined. Amplification was defined by at least a two-fold excess of the number of copies of the HER-2/neu gene with regard to the number of centromeres of chromosome 17 (Fig. 2).

For statistical analysis, Statistical Package for the Social Sciences (SPSS, Chicago, IL, USA) version 10.0 for Windows software was used. The chi-squared test was used to detect statistically significant differences between the groups, with a significance level of $\mathrm{p}<0.05$.

\section{Results}

IHC results. HER-2 staining in primary tumors was 0 in 9 $(22.5 \%)$ patients, $1^{+}$in $14(35 \%), 2^{+}$in $10(25 \%)$, and $3^{+}$in 7 (17.5\%). When $2^{+}$and $3^{+}$combined were considered HER-2 positive, 17 patients were HER-2 positive. According to the classification of grade, one $(1 / 3,33.3 \%)$ Grade 2 patient and $16(16 / 37,43.2 \%)$ Grade 3 patients were HER-2 positive. According to the classification of stage, $12(12 / 22,54.5 \%)$ pT2 patients, $2(2 / 13,15.3 \%)$ pT3 patients, and $3(3 / 5,60 \%)$ pT4 patients were HER-2 positive. Lymph node metastasis was found in 10 patients, and $3(3 / 6,50 \%)$ pT2 patients were HER-2 positive. No statistically significant difference was observed among all the classifications. However, there was a tendency for HER-2-positive patients to predominate in advanced-stage disease, although no statistically significant difference was observed $(\mathrm{P}=0.05)$ (Table II). In metastatic lymph nodes, HER-2 staining was determined as 0 in 7 (70\%) patients and $3^{+}$in $3(30 \%)$, with no patient with $1^{+}$or $2^{+}$. In addition, all primary tumors were Grade 3, and HER-2 staining was $3^{+}$in all patients with positive lymph nodes. A statistically significant difference between patients with IHC-positive primary tumors and those with IHC-positive metastatic tumors was observed $(\mathrm{P}=0.02)$ (Table III).

FISH results. In primary tumors, the signal ratio was $0-1.0$ in 4 patients $(10.0 \%), 1.1-2.0$ in $31(77.5 \%)$, and $\geq 2.0$, which was considered positive for HER-2/neu gene amplification, in $5(12.5 \%)$. According to the classification of grade, all Grade 2 patients were negative for HER-2/neu gene amplification, but 5 Grade 3 patients were positive $(5 / 37,13.5 \%)(\mathrm{P}=0.99)$. According to the classification of stage, 2 pT2 patients $(2 / 22$, $9 \%), 2$ pT3 patients $(2 / 13,15.3 \%)$, and 1 pT4 patient were positive $(1 / 5,20 \%)(\mathrm{P}=0.75)$. Lymph node metastasis was found in 10 patients, and $3 \mathrm{pN} 2$ patients were positive for HER-2/neu gene amplification $(3 / 6,50 \%)(\mathrm{P}=0.32)$. No statistically significant difference was observed among all the classifications (Table II). In all patients positive for gene amplification, IHC staining was $3^{+}$. The concordance rate of IHC $3^{+}$patients and patients positive for gene amplification by FISH was $71 \%$ (5/7). Gene amplification was not detected in 2 patients although IHC staining was $3^{+}$(Table IV). In 

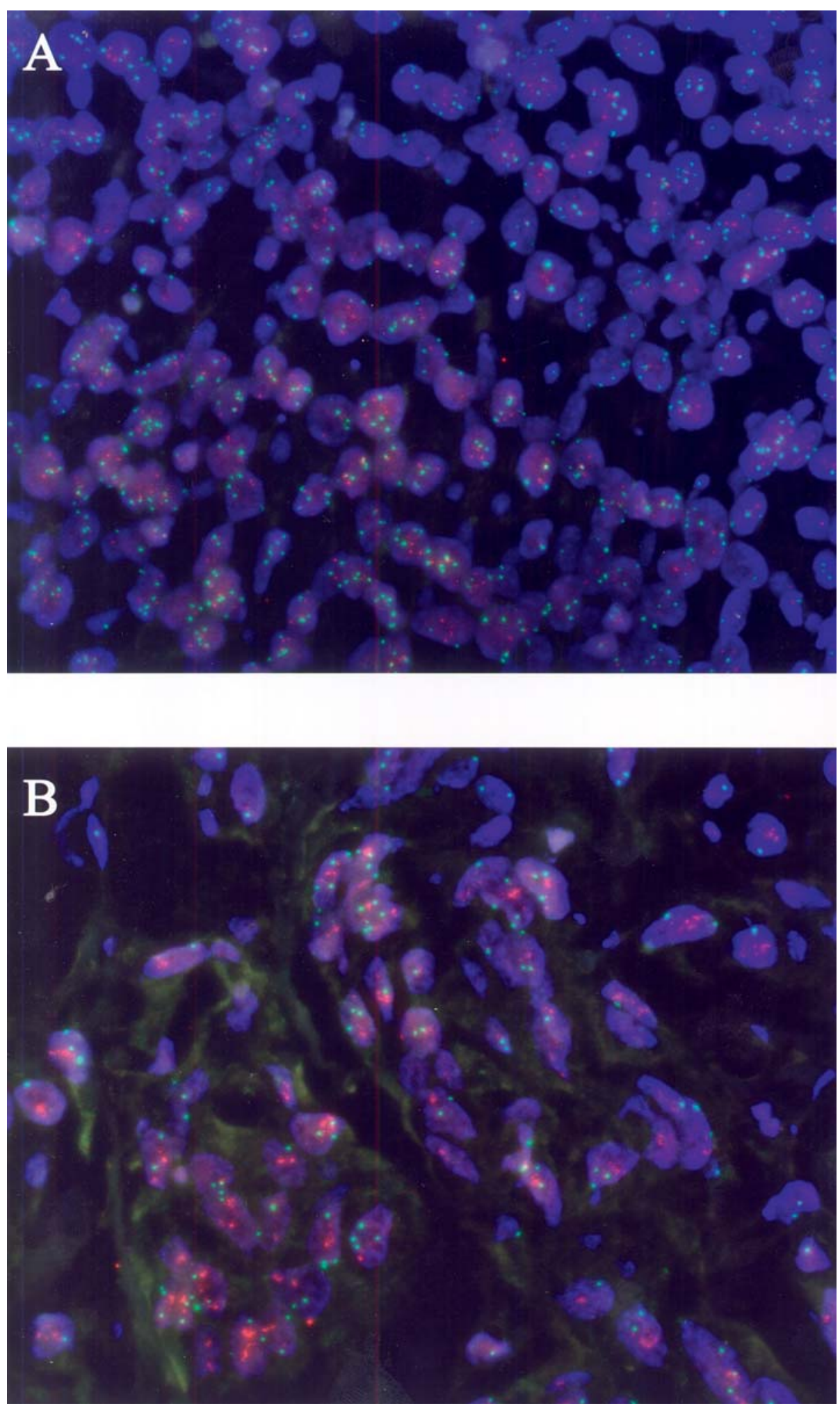

Figure 2. Fluorescent in situ hybridization of HER-2/neu on paraffin-embedded tissue sections (x400). (A) Tumor without amplification. A mean number of two signals per nucleus was observed. (B) Tumor with a high-level amplification.

metastatic lymph nodes, HER-2/neu gene amplification was $1.0-2.0$ in 7 patients $(70 \%)$ and $\geq 2.0$ in $3(30 \%)$, and the primary tumors were positive for HER-2/neu gene amplification as well, showing a statistically significant difference $(\mathrm{P}=0.02)$. These patients were similar to those who were $3^{+}$ by IHC staining (Table III).

\section{Discussion}

HER-2/neu (or HER-2) is a proto-oncogene located at chromosome $17 \mathrm{q} 21$, encoding a protein with a molecular weight of $185 \mathrm{kDa}$ which has a transmembrane receptor structure. This protein is a tyrosine kinase-type cell surface 
Table II. Results of HER-2/neu overexpression (IHC) and gene amplification (FISH) by grade and stage.

\begin{tabular}{lcccccrr}
\hline & HER-2 positive & HER-2 negative & P-value & FISH-A & FISH-NA & P-value & Total \\
\hline Grade & & & & & & & \\
G2 & $1(33.4 \%)$ & $2(66.6 \%)$ & 0.99 & $0(0 \%)$ & $3(100 \%)$ & $>0.99$ & 37 \\
G3 & $16(43.2 \%)$ & $21(56.8 \%)$ & & $5(13.5 \%)$ & $32(86.5 \%)$ & & \\
T classification & & & & & & \\
T2 & $12(54.5 \%)$ & $10(45.4 \%)$ & & $2(9.1 \%)$ & $20(90.9 \%)$ & & 22 \\
T3 & $2(15.3 \%)$ & $11(84.6 \%)$ & 0.05 & $2(15.4 \%)$ & $11(84.6 \%)$ & 0.75 & 13 \\
T4 & $3(60.0 \%)$ & $2(40.0 \%)$ & & $1(20.0 \%)$ & $4(80.0 \%)$ & & 5 \\
N classification & & & & & \\
N1 & $0(0 \%)$ & $4(100 \%)$ & 0.32 & $0(0 \%)$ & $4(100 \%)$ & 0.32 & 4 \\
N2 & $3(50 \%)$ & $3(50 \%)$ & & $3(50 \%)$ & $3(50 \%)$ & & 6 \\
\hline
\end{tabular}

FISH-A, FISH amplified; FISH-NA, FISH not amplified.

Table III. HER-2/neu overexpression (IHC) and gene amplification (FISH) in primary tumors and lymph node metastases.

\begin{tabular}{|c|c|c|c|}
\hline \multirow[b]{2}{*}{$\begin{array}{l}\text { Lymph node } \\
\text { metastases }\end{array}$} & \multicolumn{2}{|c|}{ Primary tumors } & \\
\hline & $\begin{array}{c}\text { FISH-A } \\
\text { HER-2 positive }\end{array}$ & $\begin{array}{c}\text { FISH-NA } \\
\text { HER2-negative }\end{array}$ & P-value \\
\hline
\end{tabular}

\section{FISH-A}

$\begin{array}{llll}\text { HER-2 positive } & 3 & 0 & \\ \text { FISH-NA } & & & \\ \text { HER-2 negative } & 0 & 7 & 0.02\end{array}$

Patients with lymph node metastases $(n=10)$. FISH-A, FISH amplified; FISH-NA, FISH not amplified.

receptor which has amino acid sequences similar to those of an epidermal growth factor receptor, and whose cell differentiation and proliferation are stimulated by a ligand binding to an extracellular domain. Moreover, fundamental studies have shown that HER-2 overexpression induces cell transformation and that HER-2-positive tumors are more aggressive. With regard to the distribution of HER-2 in normal tissues, HER-2 is slightly expressed only in the liver, bile duct, gastrointestinal tract, skin, genital organs and urinary tract, with limited expression in most normal tissues (14-16). Therefore, the potential for molecular targeted therapy targeting HER-2 is of great interest.

Since Slamon et al (17) reported the correlation between HER-2 (c-erbB-2) gene amplification and breast cancer with a poor outcome in 1987, HER-2 has been considered to be a poor prognostic factor in breast cancer. In addition, breast cancer with HER-2 overexpression has been reported to be resistant to hormone therapy $(18,19)$, resulting in establishment of treatment with trastuzumab (20). Currently, the methods to
Table IV. Comparison of HER-2/neu between overexpression (IHC) and gene amplification (FISH).

\begin{tabular}{lrrrrr}
\hline & \multicolumn{5}{c}{ HER-2/neu overexpression (IHC) } \\
\cline { 2 - 6 } & 0 & + & ++ & +++ & Total \\
\hline HER2/neu (FISH) & 9 & 14 & 10 & 2 & 35 \\
NA & 0 & 0 & 0 & 5 & 5 \\
A & 9 & 14 & 10 & 7 & 40 \\
Total & 9 & & & \\
\hline NA, FISH not amplified; A, FISH amplified.
\end{tabular}

analyze HER-2 in tissues include analysis of gene amplification, mRNA overexpression, and protein overexpression; however, possible methods for use on formalin-fixed paraffin sections are IHC and FISH.

It has been indicated that examination of gene amplification rather than antigen expression is a more reliable method to identify patients with HER-2-positive breast cancer $(21,22)$. However, it is inconclusive whether this result can similarly be applied to patients with cancer other than breast cancer, for example, patients with bladder cancer. Hence, we performed this analysis using both IHC staining and FISH in this study.

While HER-2/neu overexpression was observed in $12 \%$ (23) to $71 \%$ (24) of urothelial cancers, it correlated with grade and stage in some studies (25) but not in others $(26,27)$, suggesting that this field has not yet been clarified. We studied patients with invasive bladder carcinoma in this analysis, and overexpression did not correlate with grade, stage or lymph node metastasis. In the literature on comparison between IHC and FISH, Sauter et al (28) reported that HER-2/neu gene amplification was detected in only $7 \%(10 / 141)$ of patients 
with urothelial cancer (36 pTa, 42 pT1, 67 pT2-T3/20 G1, 39 $\mathrm{G} 2,46 \mathrm{G} 3$ and 6 with grade and stage unknown), whereas $43 \%(61 / 141)$ of tumors were HER-2 positive by IHC. In addition, Kruger et al (29) studied 203 patients with urothelial cancer and reported that $37 \%$ (76/203) of patients were HER-2 positive by IHC, whereas HER-2/neu gene amplification was detected in only 5\% (2/42) of patients. Moreover, de Pinieux et al (30) reported that $23 \%(15 / 64)$ of patients with invasive urothelial cancer were HER-2 positive, while HER-2/neu gene amplification was detected in $28 \%(6 / 21)$ of patients. In our study, $42.5 \%$ (17/40) of patients were HER-2 positive by IHC, and $12.5 \%$ of patients were positive for gene amplification by FISH (5/40). In comparison of HER-2 expression between IHC and FISH, it was suggested that the dissociation between gene amplification and overexpression could be related to a point mutation that leads to protein overexpression, translocation or transcriptional upregulation (28). However, it is inconclusive whether this result can be applied to patients with bladder carcinoma, because the positive controls for the Hercep test kit for IHC are breast cancer cell lines. This could be a reason for the possible dissociation. Moreover, HER-2/ neu expression is rare, and it may not be detected among extensive specimens on a glass slide in some cases because 400-fold magnification is required for observation by FISH, and because there may be a difference within the specimen slides as well. In addition, an automated analysis system may not be able to detect weak signals, and in such cases, analysis by fluorescence microscopy may also be necessary. Moreover, the dose effect caused by polysomy and DNA demethylation should be taken into consideration.

Our results suggest that performing IHC to identify IHC $3^{+}$patients first, and then performing gene amplification using FISH on the immunohistochemically stained region may be effective to accurately diagnose HER-2/neu expression in patients with invasive bladder carcinoma.

Trastuzumab is a human monoclonal antibody against the outer cell membrane of the HER-2 receptor. By binding to the receptor, this drug blocks subsequent signals to the receptor, inhibits cancer growth, and produces an anti-tumor effect, representing a molecular targeted therapeutic drug targeting HER-2. It has been indicated that examination of gene amplification rather than antigen expression is a more reliable method to identify patients with HER-2-positive breast cancer $(21,22)$ and our results suggested that $12.5 \%$ of patients with invasive bladder carcinoma may benefit from this drug. Moreover, it was suggested that patients suitable for this therapy should be identified by cost-effective IHC first, and then by performing gene amplification analysis using FISH in IHC $3^{+}$patients. In addition, efficacy of this drug can be expected even in patients with lymph node metastases, as long as the primary foci are HER-2/neu positive. Further clinical studies in various phases are expected to establish the effectiveness of treatment with trastuzumab for bladder carcinoma.

\section{References}

1. Bassi P, Ferrante GD, Piazza N, et al: Prognostic factors of outcome after radical cystectomy for bladder cancer: a retrospective study of a homogeneous patient cohort. J Urol 161: 1494-1497, 1999.
2. Ghoneim MA, el-Mekresh MM, el-Baz MA, el-Attar IA and Ashamallah A: Radical cystectomy for carcinoma of the bladder: critical evaluation of the results in 1,026 cases. J Urol 158: 393-399, 1997

3. Schuster TG, Smith DC and Montie JE: Pelvic recurrences post cystectomy: current treatment strategies. Semin Urol Oncol 19: 45-50, 2001.

4. Sternberg CN, Yagoda A, Scher HI, et al: Preliminary results of M-VAC (methotrexate, vinblastine, doxorubicin and cisplatin) for transitional cell carcinoma of the urothelium. J Urol 133: 403-407, 1985.

5. Sternberg CN, Yagoda A, Scher HI, et al: Methotrexate, vinblastine, doxorubicin, and cisplatin for advanced transitional cell carcinoma of the urothelium. Efficacy and patterns of response and relapse. Cancer 64: 2448-2458, 1989.

6. Loehrer PJ Sr, Einhorn LH, Elson PJ, et al: A randomized comparison of cisplatin alone or in combination with methotrexate, vinblastine, and doxorubicin in patients with metastatic urothelial carcinoma: a cooperative group study. J Clin Oncol 10: 1066-1073, 1992.

7. Saxman SB, Propert KJ, Einhorn LH, et al: Long-term followup of a phase intergroup study of cisplatin alone or in combination with methotrexate, vinblastine, and doxorubicin in patients with metastatic urothelial carcinoma: a cooperative group study. J Clin Oncol 15: 2564-2569, 1997.

8. Bajorin DF, McCaffrey JA, Dodd PM, et al: Ifosfamide, paclitaxel, and cisplatin for patients with advanced transitional cell carcinoma of the urothelial tract: final report of a phase trial evaluating two dosing schedules. Cancer 88: 1671-1678, 2000.

9. von der Maase H, Hansen SW, Roberts JT, et al: Gemcitabine and cisplatin versus methotrexate, vinblastine, doxorubicin, and cisplatin in advanced or metastatic bladder cancer: results of a large, randomized, multinational, multicenter, phase III study. J Clin Oncol 18: 3068-3077, 2000.

10. von der Maase H, Sengelov L, Roberts JT, et al: Long-term survival results of a randomized trial comparing gemcitabine plus cisplatin, with methotrexate, vinblastine, doxorubicin, plus cisplatin in patients with bladder cancer. J Clin Oncol 23: 4602-4608, 2005.

11. Epstein JI, Amin MB, Reuter VR and Mostofi FK: The world health organization / international society of urological pathology consensus classification of urothelial (transitional cell) neoplasms of the urinary bladder. Am J Surg Pathol 22: 1435-1448, 1998.

12. Sobin LH and Wittekind C (eds): TNM Classification of Malignant Tumors. 6th edition. Wiley-Liss, New York, pp199-202, 2002.

13. Carter P, Presta L, Gorman CM, et al: Humanization of an antip185HER2 antibody for human cancer therapy. Proc Natl Acad Sci USA 89: 4285-4289, 1992.

14. Natali PG, Nicotra MR, Bigotti A, et al: Expression of the p185 encoded by HER 2 oncogene in normal and transformed human tissues. Int J Cancer 45: 457-461, 1990.

15. Press MF, Cordon-Cardo C and Slamon DJ: Expression of the HER-2/neu proto-oncogene in normal human adult and fetal tissues. Oncogene 5: 953-962, 1990.

16. Gorgoulis VG, Barbatis C, Poulias I and Karameris AM: Molecular and immunohistochemical evaluation of epidermal growth factor receptor and c-erb-B-2 gene product in transitional cell carcinomas of the urinary bladder: a study in Greek patients. Mod Pathol 8: 758-764, 1995.

17. Slamon DJ, Clark GM, Wong SG, Levin WJ, Ullrich A and McGuire WL: Human breast cancer: correlation of relapse and survival with amplification of the HER-2/neu oncogene. Science 235: 177-182, 1987

18. Slamon DJ, Godolphin W, Jones LA, et al: Studies of the HER-2/ neu proto-oncogene in human breast and ovarian cancer. Science 244: 707-712, 1989

19. Press MF, Bernstein L, Thomas PA, et al: HER-2/neu gene amplification characterized by fluorescence in situ hybridization: poor prognosis in node-negative breast carcinomas. J Clin Oncol 15: 2894-2904, 1997.

20. Slamon DJ, Leyland-Jones B, Shak S, et al: Use of chemotherapy plus a monoclonal antibody against HER2 for metastatic breast cancer that overexpresses HER2. N Engl J Med 344: 783-792, 2001.

21. Mass RD, Press MF, Anderson S, et al: Evaluation of clinical outcomes according to HER-2 detection by fluorescence in situ hybridization in women with metastatic breast cancer treated with trastuzumab. Clin Breast Cancer 6: 240-246, 2005. 
22. Dybdal N, Leiberman G, Anderson S, et al: Determination of HER2 gene amplification by fluorescence in situ hybridization and concordance with the clinical trials immunohistochemical assay in women with metastatic breast cancer evaluated for treatment with trastuzumab. Breast Cancer Res Treat 93: 3-11, 2005.

23. Lipponen P, Eskelinen M, Syrjanen S, Tervahauta A and Syrjanen K: Use of immunohistochemically demonstrated c-erbB-2 oncoprotein expression as a prognostic factor in transitional cell carcinoma of the urinary bladder. Eur Urol 20: 238-242, 1991

24. Gandour-Edwards R, Lara PN Jr, Folkins AK, et al: Does HER2/neu expression provide prognostic information in patients with advanced urothelial carcinoma? Cancer 95: 1009-1015, 2002.

25. Miyamoto H, Kubota Y, Noguchi S, et al: C-ERBB-2 gene amplification as a prognostic marker in human bladder cancer. Urology 55: 679-683, 2000.

26. Ioachim E, Charchanti A, Stavropoulos NE, Skopelitou A, Athanassiou ED and Agnantis NJ: Immunohistochemical expression of retinoblastoma gene product $(\mathrm{Rb}), \mathrm{p} 53$ protein, MDM2, c-erbB-2, HLA-DR and proliferation indices in human urinary bladder carcinoma. Histol Histopathol 15: 721-727, 2000 .
27. Koyuncuoglu M, Kargi A, Cingoz S and Kirkali Z: Investigation of p53, c-erbB-2, PCNA immunoreactivity, DNA content, AgNOR and apoptosis in bladder carcinoma as prognostic parameters. Cancer Lett 126: 143-148, 1998.

28. Sauter G, Moch H, Moore D, et al: Heterogeneity of erbB-2 gene amplification in bladder cancer. Cancer Res 53: 2199-2203, 1993.

29. Kruger S, Weitsch G, Buttner H, et al: Overexpression of c-erbB-2 oncoprotein in muscle-invasive bladder carcinoma: relationship with gene amplification, clinicopathological parameters and prognostic outcome. Int J Oncol 21: 981-987, 2002.

30. de Pinieux G, Colin D, Vincent-Salomon A, et al: Confrontation of immunohistochemistry and fluorescence in situ hybridization for the assessment of HER-2/neu (c-erbb-2) status in urothelial carcinoma. Virchows Arch 444: 415-419, 2004. 